Dear author,

Please note that changes made in the online proofing system will be added to the article before publication but are not reflected in this PDF.

We also ask that this file not be used for submitting corrections. 


\title{
Motherhood status moderates the relationship between perfectionistic self-presentation and breast size dissatisfaction
}

\author{
Q2 Caterina Lombardo ${ }^{\mathrm{a}, *}$, Maria Serena Panasiti ${ }^{\mathrm{b}}$, Mariacarolina Vacca ${ }^{\mathrm{a}}$, Caterina Grano ${ }^{\mathrm{a}}$, \\ Viren Swami ${ }^{c, d}$ \\ a Department of Psychology, Sapienza University of Rome, Rome, Italy \\ b Santa Lucia Foundation, IRCSS, Rome, Italy \\ ' School of Psychology and Sport Science, Anglia Ruskin University, Cambridge, United Kingdom \\ d Centre for Psychological Medicine, Perdana University, Serdang, Malaysia
}

\section{Article history:}

Received 19 November 2018

Received in revised form 17 May 2019

Accepted 17 May 2019

Available online $\mathrm{xxx}$

\section{Keywords:}

Breast size dissatisfaction

Perfectionism

Self-presentation

Motherhood

\begin{abstract}
A B S T R A C T
Perfectionistic self-presentation refers to a desire to create an image of flawlessness in the eyes of the others and has been associated with more negative body image. We extended previous research by examining associations between perfectionistic self-presentation and breast size dissatisfaction, and also examined whether motherhood status moderated this association. A total of 484 Italian women (age $M=40.39, S D=13.73$; mothers $n=53.9 \%$ ) completed measures of perfectionistic self-presentation (perfectionistic self-promotion, nondisplay of imperfection, and nondisclosure of imperfection) and breast size dissatisfaction. Preliminary analyses indicated that a majority of the sample (69.2\%) reported breast size dissatisfaction, with $44.4 \%$ and $24.4 \%$ desiring larger and smaller breasts, respectively, than they currently had. Only perfectionistic self-promotion and nondisplay of imperfection were significantly correlated with breast size dissatisfaction. Both associations were additionally moderated by motherhood status, with associations being significant in non-mothers but not in mothers. Our findings suggest that motherhood may help decouple the link between perfectionistic self-presentation and breast size dissatisfaction. Future studies should assess whether this effect is due to an enhanced maternal view of breasts that emphasises nurturing and biological functions or a result of weaker investment in sociocultural norms on physical appearance.
\end{abstract}

(C) 2019 Published by Elsevier Ltd.

\section{Introduction}

In many cultures, women's breasts are invested with social and cultural meanings that shape experiences of embodiment (Grogan, Gill, Kilgraff, \& Whalley, 2013; Millsted \& Frith, 2003). In particular, women's breasts are frequently defined as objects of male sexual interest and pleasure, with larger-than-average breasts prized as markers of sexuality and femininity (Swami \& Tovée, 2013). To the extent that women internalise such ideals of breast size, it may contribute to breast size dissatisfaction, which can be conceptualised as a facet of negative body image (Swami et al., 2015). For example, studies of women in the United States (Frederick et al., 2008), the United Kingdom (Swami et al., 2015), and Brazil (Junqueira et al., 2019) indicate that most women are dissatisfied with their breasts and desire larger breasts. Thus, focusing on breast size dissatisfac-

\footnotetext{
* Corresponding author at: Department of Psychology, Sapienza University of Rome, Via dei Marsi 78, 00185, Rome, Italy.

E-mail address: caterina.lombardo@uniroma1.it (C. Lombardo).
}

tion is important because it is associated with negative body image (Forbes \& Frederick, 2008) and poorer psychological well-being (Junqueira et al., 2019; Swami et al., 2015), and it is also predictive of negative behavioural outcomes (e.g., lower likelihood of breast self-examination) over-and-above body dissatisfaction (Swami \& Furnham, 2018).

To date, no research has focused on antecedents of breast size dissatisfaction. On the basis of evidence linking breast size dissatisfaction to body dissatisfaction (Swami \& Furnham, 2018), it might be suggested that antecedents of body dissatisfaction will also act as antecedents of breast size dissatisfaction. In this vein, perfectionism and perfectionistic self-presentation have been highlighted as important antecedents of body dissatisfaction. Perfectionism is defined as the setting of excessively high standards and the tendency to make overly critical self-evaluations (Hewitt \& Flett, 1991). In the domain of body image specifically, it may refer to a belief that a perfect body is an attainable goal (Millsted \& Frith, 2003). Perfectionistic self-presentation, on the other hand, involves an outward expression of perfectionism in the eyes of others (Hewitt et al., 2003). This trait consists of three dimen- 
sions: perfectionistic self-promotion (promoting one's perfection to others), nondisclosure of imperfection (avoidance of disclosure of imperfections to others), and nondisplay of imperfection (avoidance of displaying imperfections to others). Studies have reported that perfectionistic self-presentation - and particularly the facet of nondisplay of imperfection - is significantly associated with more negative body image (e.g., Ferreira, Pinto-Gouveia, \& Duarte, 2014; Skouteris, Carr, Wertheim, Paxton, \& Duncombe, 2009) and greater consideration of cosmetic surgery in women (Swami \& Tovée, 2013). Although trait perfectionism has been reported to be a risk factor for disordered eating, the relationship between perfectionistic self-presentation and negative body image in women appears to occur independently of trait perfectionism (Skouteris et al., 2005). To date, however, research has not examined potential associations between perfectionistic self-presentation and breast size dissatisfaction.

Another factor that may influence perfectionistic selfpresentation and its relationship with breast size dissatisfaction is motherhood status. Studies suggest that body dissatisfaction is common during and after pregnancy (Junqueira et al., 2019), particularly as pregnancy-and postpartum-related weight gain is perceived as an "imperfection" that transgresses societallyprescribed ideals of appearance (Chang, Chao, \& Kenney, 2006). At the same time, increased breast size during pregnancy has been associated with increased body satisfaction (Chang et al., 2006), because women perceived themselves as moving closer to societally-constructed ideals of breast appearance. Postpartumrelated changes, such as breastfeeding, may also heighten acknowledgement of the functionality - as opposed to the aesthetics - of breasts and the body (e.g., Harrison, Obeid, Haslett, McLean, \& Clarkin, 2019) and consequently improve breast size satisfaction. Indeed, other studies indicate that pregnant women experience stable, or even diminished appearance dissatisfaction (e.g., Swami, Cavelti, Taylor, \& Tovée, 2005) and that, in this population, body functionality may buffer the negative effects of self-objectification (Sherry et al., 2009). It is possible that becoming a mother provides alternative parameters for bodily self-evaluations (e.g., the body as a site of biological function rather than aesthetic investment) and that mothers are more sensitive to the function of breast relative to the health and comfort of the new-born (Sherry et al., 2009).

Of course, much of this remains conjecture at this stage. To move beyond conjecture, we conducted an initial, exploratory examination of the associations between perfectionistic self-presentation and breast size dissatisfaction in a sample of Italian women. We hypothesised that perfectionistic self-presentation - particularly the facet of nondisplay of imperfection - would be significantly associated with breast size dissatisfaction. In addition, we considered the impact of motherhood status and hypothesised that the status of being a mother would moderate the relationship between perfectionistic self-presentation and breast size dissatisfaction. That is, based on the view that motherhood promotes a functional view of the breasts, we expected that being a mother would decouple the link between perfectionistic self-presentation and breast size dissatisfaction.

\section{$112 \quad$ 2. Method}

\subsection{Participants}

We recruited a community sample of 484 Italian women ranging in age from 18 to 70 years $(M=40.00, S D=13.73)$ and in self-reported body mass index (BMI) from 15.62 to $47.88 \mathrm{~kg} / \mathrm{m}^{2}$ $(M=23.23, S D=4.26)$. The majority self-reported as being White $(87.0 \%)$ and, at the time of recruitment, $8.5 \%$ had completed primary schooling, $46.0 \%$ had completed high school, $8.5 \%$ had an undergraduate degree, $21.0 \%$ had a postgraduate degree, and the remainder were in full-time education. Just over half the sample (53.9\%) reported having children (range $=1-9, M=1.86, S D=0.84$ ).

\subsection{Measures}

\subsubsection{Breast size dissatisfaction}

Dissatisfaction with one's breast size was measured using the Breast Size Rating Scale (BSRS; Swami \& Furnham, 2018). This is a figural rating scale consisting of 14 greyscale, computer-generated images of women varying in breast size alone. Participants were asked to rate the image that most closely matched their own breast size and the image that most closely matched their desired breast size on a 14-point scale (1 represented the figure with the smallest breast size, 14 represented the figure with the largest breast size). A measure of breast size dissatisfaction was computed as the absolute difference between actual and ideal ratings (Swami \& Furnham, 2018), so that higher scores reflect greater dissatisfaction. Scores on the BSRS have been shown to have adequate indices of convergent and construct validity in adult women (Mallinger \& DeWyze, 1992; Swami \& Furnham, 2018).

\subsubsection{Perfectionistic self-presentation}

The survey included the Perfectionistic Self-Presentation Scale (PSPS; Hewitt et al., 2003; Italian translation: Borroni et al., 2016), a 27-item measure with three subscales capturing perfectionistic self-promotion (10 items; sample item: "I strive to look perfect to others"), nondisplay of imperfection (10 items; sample item: "I hate to make errors in public"), and nondisclosure of imperfection (7 items; sample item: "I should always keep my problems to myself"). Items were rated on a 7 -point scale ( $1=$ totally disagree, $7=$ totally agree) and subscale scores were computed as the mean of relevant items. Scores on the Italian version of the PSPS have been shown to have a 3-dimensional factor structure mirroring the parent version, adequate internal consistency coefficients, and good patterns of construct validity in adults (Borroni et al., 2016). In this study, omega was .73 (95\% CI: .71, .75) for nondisclosure of imperfection, $.76(95 \% \mathrm{CI}: .74, .78)$ for perfectionistic self-promotion, and .77 (95\% CI: .74, .80) for nondisplay of imperfection.

\subsubsection{Demographics}

Participants were asked to report their age, ethnicity, highest educational qualification, motherhood status, height, and weight.

\subsection{Procedures}

The project was approved by the relevant departmental ethics committee. The BSRS instructions and items were translated from English into Italian using the back-translation technique (Brislin, 1970). Data were collected as part of a larger multicentre study between February and October 2018, and participants were told that the aim was to investigate the cross-cultural factors linked to breast size dissatisfaction. Potential participants who met inclusion criteria (of adult age, Italian citizens, and self-reported fluency in Italian) were recruited from areas of congregate activities (e.g., shopping malls, train stations) in and around Rome. They provided written informed consent and completed a paper-and-pencil questionnaire in portable stations set up for the purposes of the study. Questionnaires were anonymous and required an average of $20 \mathrm{~min}$ to complete. Upon completion, participants were provided with debrief information. All participants took part on a voluntary basis and were not remunerated. 
Table 1

Bivariate correlations included in the present study and descriptive statistics as a function of motherhood status.

\begin{tabular}{|c|c|c|c|c|c|c|c|c|}
\hline & (1) & (2) & (3) & (4) & (5) & (6) & \multicolumn{2}{|l|}{$(7)$} \\
\hline \multicolumn{9}{|c|}{ (1) Breast size dissatisfaction } \\
\hline \multicolumn{2}{|c|}{ (2) Perfectionist self-promotion } & $.14^{*}$ & & & & & & \\
\hline \multicolumn{2}{|c|}{ (3) Nondisplay of imperfection } & $.16^{*}$ & $.72^{*}$ & & & & & \\
\hline \multicolumn{2}{|c|}{ (4) Nondisclosure of imperfection } & .06 & $.52^{*}$ & $.56^{*}$ & & & & \\
\hline \multicolumn{2}{|c|}{ (5) Age } & -.02 & $-.09^{*}$ & -.03 & .01 & & & \\
\hline \multicolumn{2}{|c|}{ (6) Body mass index } & .02 & .01 & .06 & $.11^{*}$ & $.26^{* *}$ & & \\
\hline \multicolumn{2}{|c|}{ (7) Actual breast size } & -.01 & .02 & .01 & $.10^{*}$ & $.26^{* *}$ & $.56^{* *}$ & \\
\hline \multirow[t]{2}{*}{ Mothers } & $M$ & 2.23 & 3.30 & 3.71 & 3.59 & 48.8 & 24.1 & 7.39 \\
\hline & $S D$ & 2.35 & 1.16 & 1.11 & 1.08 & 8.43 & 4.07 & 4.05 \\
\hline \multirow[t]{3}{*}{ Non-mothers } & $M$ & 2.51 & 3.55 & 3.83 & 3.55 & 30.5 & 22.3 & 5.66 \\
\hline & $S D$ & 2.32 & 1.20 & 1.09 & 1.03 & 11.6 & 4.27 & 3.83 \\
\hline & $t$ & -1.10 & $-2.30^{*}$ & -1.30 & 0.40 & $19.60^{* *}$ & $4.65^{* *}$ & $4.79 * *$ \\
\hline
\end{tabular}

Note. ${ }^{*} p<.01 .{ }^{*} p<.001$.

\subsection{Statistical analyses}

Statistical significance of group differences was evaluated by means of independent-samples $t$-test. Pearson linear correlation coefficients were used to test the association between variables. Moderation analyses were computed using PROCESS 3.0. A 1000sample bootstrapping approach was used, and 95\% low and high confidence intervals (LCI, UCI) were estimated through the percentile method (Hayes, 2013).

\section{Results}

\subsection{Preliminary analysis}

Missing values constituted $0.6 \%$ of the total dataset and were treated with pairwise deletion. In our sample, $30.8 \%$ of the sample reported no breast size dissatisfaction and $69.2 \%$ reported breast size dissatisfaction. Of the latter, $44.4 \%$ desired larger breast size and $24.4 \%$ desired smaller breast size. The mean rating for current breast size was $6.59(S D=4.04$, skewness $=0.32$, kurtosis -1.09), and the mean ideal breast size rating on the BSRS was $7.12(S D=2.87$, skewness $=1.18$, kurtosis $=-0.27)$. Bivariate correlations were computed between absolute breast size dissatisfaction scores and perfectionistic self-presentation dimensions. As reported in Table 1, breast size dissatisfaction was significantly and positively associated with perfectionistic self-promotion and nondisplay of imperfection (although the strength of the associations was weak), but not with nondisclosure of imperfection. An independent samples $t$-test indicated that mothers had significantly lower self-promotion scores than non-mothers, $t(478)=2.28, p=$ $.023, d=0.20$. There were no significant differences between mothers and non-mothers on nondisplay of imperfection, $t(475)=1.23$, $p=.219, d=0.11$, nondisclosure of imperfection, $t(482)=0.40, p=$ $.689, d=0.03$, and breast size dissatisfaction, $t(478)=1.10, p=.269$, $d=0.10$ (see Table 1 ). As the BSRS does not reflect the direction of the dissatisfaction, separate bivariate correlations for women who wanted bigger or smaller breast sizes are reported in Supplemental Materials (see Supplementary Tables 3 and 4).

\subsection{Moderation analysis}

Separate moderated models were used to examine whether motherhood status moderated the relationship between perfectionistic self-promotion or nondisplay of imperfection, and breast size dissatisfaction, with age and BMI as covariates. All variables were continuous and centred prior to analyses. For perfectionistic self-promotion, the model was statistically significant, $F(5$, $467)=3.79, p=.002, R^{2}=.04$. Higher perfectionistic self-promotion was significantly related to greater breast size dissatisfaction, but this relationship was moderated by being a mother (see
Table 2

Results of the moderation analyses with motherhood status (mothers, non-mothers) on the relationships between breast size dissatisfaction and perfectionist selfpresentation and nondisplay of imperfection.

\begin{tabular}{lllll}
\hline & $\beta$ & $S E$ & $t$ & $p$ \\
\hline Perfectionist self-presentation & & & & \\
Motherhood status & .05 & .06 & 0.75 & .457 \\
Perfectionist self-promotion & .13 & .05 & 2.91 & .003 \\
Motherhood $\times$ Perfectionist self-promotion & .13 & .04 & 2.86 & .005 \\
Age & .02 & .06 & 0.27 & .782 \\
Body mass index & .03 & .05 & 0.55 & .580 \\
Nondisplay of imperfection & & & & \\
Motherhood status & .06 & .06 & 0.91 & .361 \\
Nondisplay of imperfection & .16 & .04 & 3.67 & .001 \\
Motherhood $\times$ Nondisplay of imperfection & .10 & .04 & 2.36 & .018 \\
Age & .01 & .06 & .069 & .944 \\
Body mass index & .02 & 05 & .427 & .669 \\
\hline
\end{tabular}

Table 2). Simple slope analysis indicated that, while the relationship between perfectionistic self-promotion and breast size dissatisfaction was significant in non-mothers $(\beta=.27, S E=.06, t=4.19, p<$ $.001, \mathrm{LCI}=.14, \mathrm{UCI}=.39)$, in mothers it was nonsignificant $(\beta=$ $.01, S E=.06, t=0.19, p=.847, \mathrm{LCI}=-.011, \mathrm{UCI}=.013$ ) (see Fig. 1 ). For nondisplay of imperfection, the model was also significant, $F(5$, $464)=4.25, p<.001, R^{2}=.04$. Results indicated that nondisplay of imperfection was not significantly related to breast size dissatisfaction, although the relationship was moderated by motherhood status (see Table 2). Simple slope analysis indicated that, while the relationship between nondisplay of imperfection and breast size dissatisfaction was significant in non-mothers $(\beta=.27, S E=.06$, $t=4.21, p<.001, \mathrm{LCI}=.14, \mathrm{UCI}=.40)$, in mothers it was nonsignificant $(\beta=.06, S E=.06, t=1.09, p=.272, \mathrm{LCI}=-.05$, UCI $=.18$ ) (see Fig. 2). We also ran our analyses separately for mothers with a single versus more than one child and found that the relationship between perfectionistic self-presentation or nondisplay of imperfection and breast size dissatisfaction becomes nonsignificant in the latter group (see Supplementary Table 5).

\section{Discussion}

A majority of women in our Italian sample were dissatisfied with their breast size, with $44.4 \%$ desiring larger breasts than they currently had. This is somewhat lower than data from samples of university students in United Kingdom (Swami \& Furnham, 2018, Studies 2 and $3: 49.7 \%$ and 54.3\%, respectively) and Brazil (Mallinger \& DeWyze, 1992: 65.5\%). Furthermore, over $24.4 \%$ of participants wanted smaller breasts, which is slightly lower compared to British women (Swami \& Furnham, 2018, Studies 2 and 3: 26.9\% and $30.2 \%$, respectively). The lower proportion of women desiring larger breasts in this study may be due to sampling differences with previous research: previous studies have relied on college-aged women, 


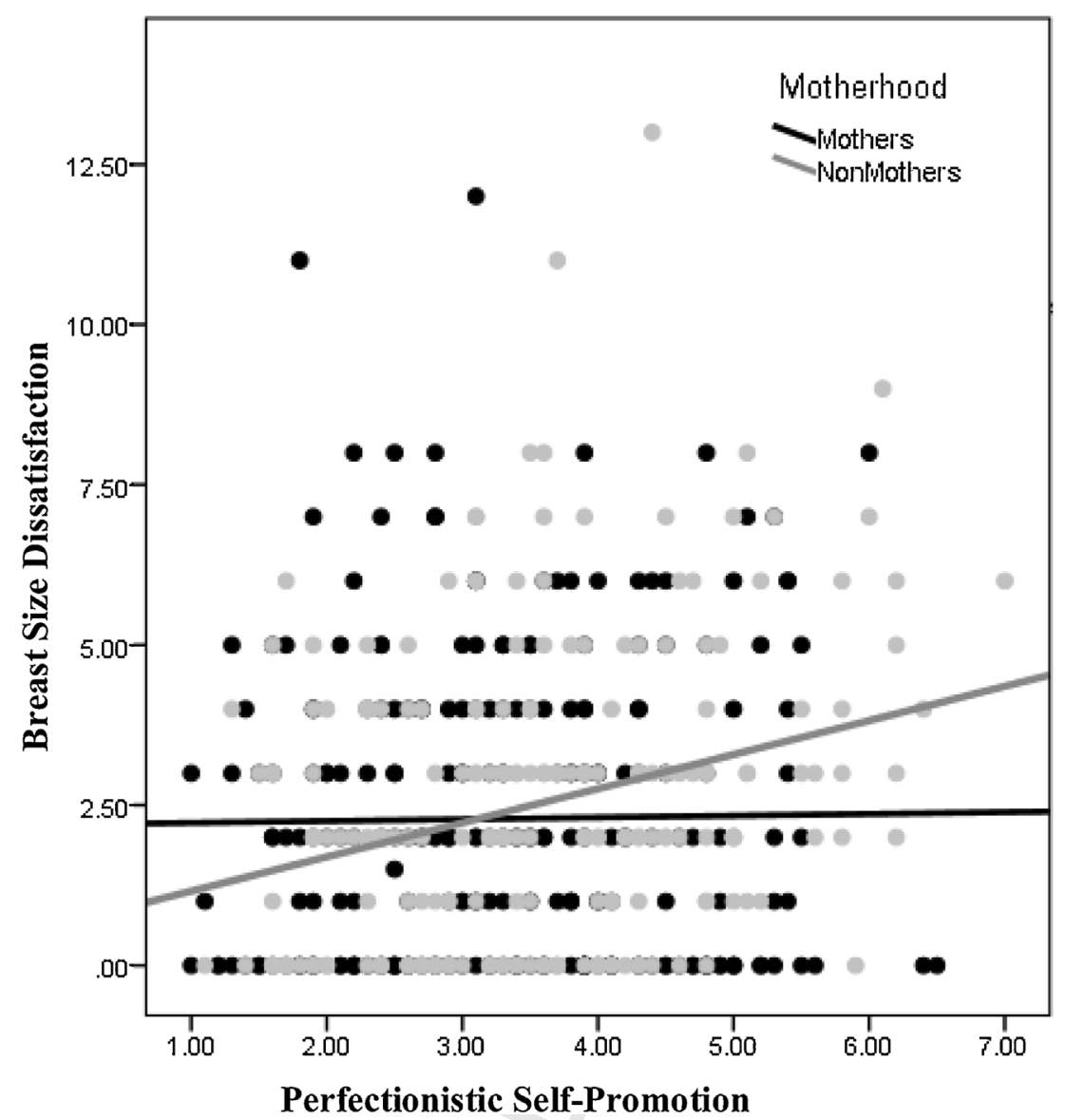

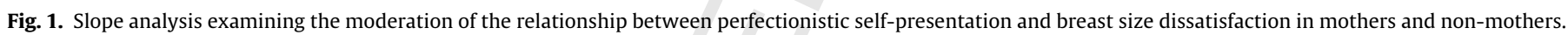

but breast composition (e.g., shape, droopiness) changes with age and this might account for cross-study differences. Cultural differences may also have played a role, although it should be noted that Italian women and men appear to idealise larger breasts as attractive (Rubin \& Steinberg, 2011). Further research using comparable recruitment methods would help to provide a clearer picture of cross-cultural differences in breast size dissatisfaction.

Our findings also indicate that perfectionistic self-presentation may be considered factor highly related with breast size dissatisfaction. In fact, two of three dimensions of perfectionistic self-presentation, namely self-promotion and nondisplay of imperfection were significantly associated with greater breast size dissatisfaction. This is consistent with previous work suggesting that facets of perfectionistic self-presentation are significantly associated with more negative body image (e.g., Ferreira et al., 2014; Skouteris et al., 2005). It might be suggested that a need to promote one's perfection to others leads dysfunctional cognitive patterns (Skouteris et al., 2005), which in turn contribute to greater breast size dissatisfaction. It should be noted, however, that previous findings evidence only the predictive role of nondisplay of imperfection for negative body image, while in the present study self-promotion also significantly predicted breast size dissatisfaction. We speculate that, for those seeking to demonstrate bodily perfection to others, breast size may be difficult to conceal compared to other bodily imperfections (e.g., perceived imperfection of the skin that may be concealed through cosmetics). Nevertheless, future studies should further investigate these specific associations between promotion-focused (i.e., perfectionistic self-promotion) and prevention-focused perfectionism (i.e., nondisclosure of imperfection) and breast size dissatisfac- tion, particularly as these facets accounted for a small proportion of variance. Moreover, the relationship between nondisplay of imperfection and self-promotion in our sample was large $(r=.72)$, suggesting that self-promotion may have accounted for a significant portion of variance only due to its shared variance with nondisplay of imperfection.

Our results also indicated that motherhood status moderated the relationships between perfectionistic facets and breast size dissatisfaction. More specifically, the associations were significant in non-mothers only. This is consistent with the fact that becoming a mother results in changes to the appearance of the breasts, particularly in terms of size (see Raposio, Belgrano, Santi, \& Chiorri, 2004), as we see also in our sample, which may attenuate the link between perfectionistic self-presentation and breast size dissatisfaction. It is also possible that the experience of motherhood may help women feel less strongly invested in sociocultural norms of appearance or develop self-evaluative criteria that are less strongly linked to appearance. More importantly, becoming a mother - and particularly the experience of breastfeeding - may focus mothers' attention on breast functionality (i.e., a maternal view of breasts that emphasises nurturing) and reduce preoccupation with the sexual uses of breasts (Harrison et al., 2019), which may again impact the association between perfectionistic self-presentation and breast size dissatisfaction. For example, qualitative research with Canadian mothers has shown that motherhood affords opportunities to develop greater appreciation of the breasts and body, particularly if their bodies performed maternal functions well (Fox \& Neiterman, 2015). Consistent with this interpretation are our findings, reported in Supplementary Materials, that the relationship between perfectionistic self-presentation and breast size 


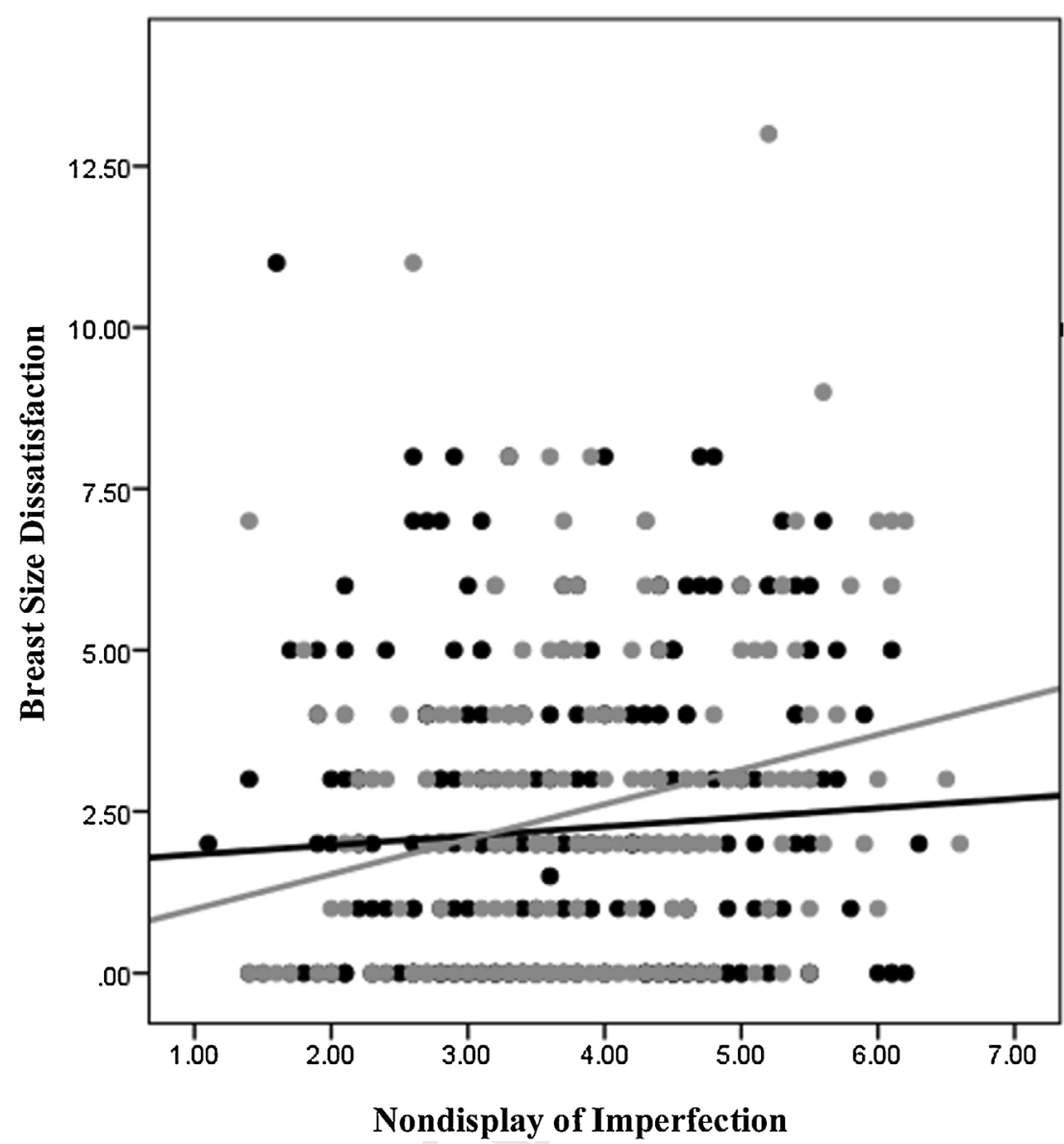

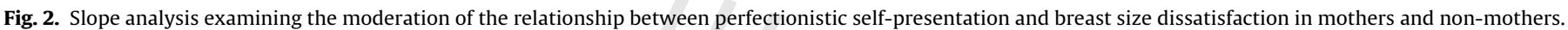

dissatisfaction becomes nonsignificant in mothers who have more than one child. In light with objectification theory (Fredrickson \& Roberts, 1997), and the self-objectification construct in particular, we may also speculate that after pregnancy, women who are able to divest from self-objectification, or reject the ideal of thinness and adopt more realistic values related to appearance, may also experience a maintenance or reduction of body dissatisfaction.

We acknowledge that this study was largely exploratory, although our findings point to a number of interesting avenues that could be explored in future research. Chief among these is the impact of motherhood on embodiment, such as changes in their appreciation of the functionality of their body (Alleva, Tylka, \& Kroon Van Diest, 2017) and body agency (Talmon \& Ginzburg, 2018), which has received limited focus in the body image literature. Future research could also examine the potential difference between body and breast size dissatisfaction in mothers versus non-mothers, and the impact of breast feeding, time since becoming a mother, identification with the maternal role, and post-pregnancy breast changes on breast size dissatisfaction. Furthermore, this work used a cross-sectional design, and prospective studies are required to confirm our findings. Another weakness is the use of self-report measures which may be subject to recall bias and social desirability effects. We further suggest that the present study could be developed through the inclusion of a measure of trait perfectionism, as well as contingent self-worth (i.e., a person's judgement of their self-worth being tied to success or failure in a given realm), which may be both associated with perfectionistic self-presentation. More broadly, we suggest that further research is needed into the antecedents of breast size dissatisfaction in diverse sociodemographic groups. Such research should aim to identify factors that may protect women from breast size dissatisfaction.

\section{Conflict of interest declaration}

The authors declare that there are no conflicts of interest.

\section{Appendix A. Supplementary data}

Supplementary material related to this article can be found, in the online version, at doi:https://doi.org/10.1016/j.bodyim.2019. 05.005 .

\section{References}

Alleva, J. M., Tylka, T. L., \& Kroon Van Diest, A. M. (2017). The Functionality Appreciation Scale (FAS): Development and psychometric evaluation in U.S. community women and men. Body Image, 23, 28-44. http://dx.doi.org/10. 1016/j.bodyim.2017.07.008

Borroni, S., Bortolla, R., Lombardi, L. M. G., Somma, A., Maffei, C., \& Fossati, A. (2016). The Italian version of the Perfectionist Self-Presentation Scale: Psychometric properties and its associations with pathological narcissism and adult attachment in an adult non clinical sample. Personality and Mental Health, 10, 130-141. http://dx.doi.org/10.1002/pmh.1328

Brislin, R. W. (1970). Back-translation for cross-cultural research. Journal of Cross-Cultural Psychology, 1, 185-216. http://dx.doi.org/10.1177/ 135910457000100301

Chang, S. R., Chao, Y. M. Y., \& Kenney, N. J. (2006). “I am a woman and I'm pregnant”: Body image of women in Taiwan during the third trimester of pregnancy. Birth, 33, 147-153. http://dx.doi.org/10.1111/j.0730-7659.2006.00087.x

Ferreira, C., Pinto-Gouveia, J., \& Duarte, C. (2014). Self-criticism, perfectionism and eating disorders: The effect of depression and body dissatisfaction. International Journal of Psychology and Psychological Therapy, 14, 409-420.

Forbes, G. B., \& Frederick, D. A. (2008). The UCLA body project II: Breast and body dissatisfaction among African, Asian, European, and Hispanic American college women. Sex Roles, 58, 449-457. http://dx.doi.org/10.1007/s11199-007-9362-6

Fox, B., \& Neiterman, E. (2015). Embodied motherhood: Women's feelings about their postpartum bodies. Gender and Society, 29, 670-693. http://dx.doi.org/10. $1177 / 0891243215591598$ 
G Model

BODYIM 10461-6

6

C. Lombardo et al. / Body Image $x x x(2019) x x x-x x x$

373

Frederick, D. A., Peplau, A., \& Lever, J. (2008). The Barbie mystique: Satisfaction with breast size and shape across the lifespan. International Journal of Sexual Health, 20, 200-211. http://dx.doi.org/10.1080/19317610802240170

Fredrickson, B. L., \& Roberts, T.-A. (1997). Objectification theory: Toward understanding women's lived experiences and mental health risks. Psychology of Women Quarterly, 21, 173-206. http://dx.doi.org/10.1111/j.1471-6402.1997. tb00108.x

Grogan, S., Gill, S., Brownbridge, K., Kilgariff, S., \& Whalley, A. (2013). Dress fit and body image: A thematic analysis of women's accounts during and after trying on dresses. Body Image, 10, 380-388. http://dx.doi.org/10.1016/j.bodyim.2013. 03.003

Harrison, M. E., Obeid, N., Haslett, K., McLean, N., \& Clarkin, C. (2019). Embodied motherhood: Exploring body image in pregnant and parenting youth. Journal of Pediatric and Adolescent Gynecology, 32, 44-50. http://dx.doi.org/10.1016/j. jpag.2018.08.007

Hayes, A. F. http://www.afhayes.com, 2013

Hewitt, P. L., Flett, G. L., Sherry, S. B., Habke, M., Parkin, M., Lam, M., . . \& Stein, M. B. (2003). The interpersonal expression of perfection: Perfectionistic self-presentation and psychological distress. Journal of Personality and Social Psychology, 84, 1303-1325. http://dx.doi.org/10.1037/0022-3514.84.6.1303

Hodgkinson, E. L., Smith, D. M., \& Wittkowski, A. (2014). Women's experiences of their pregnancy and postpartum body image: A systematic review and meta-analysis. BMC Pregnancy and Childbirth, 14, 330. http://dx.doi.org/10. 1186/1471-2393-14-330

Junqueira, A. C. P., Laws, M. F., Almeida, S. S., Braga Costa, T. M., da Cunha, M. C. F., \& Swami, V. (2019). Psychometric properties of the Breast Size Rating Scale (BSRS) in Brazilian university women. Body Image, 28, 34-38. http://dx.doi.org/ 10.1016/j.bodyim.2018.11.004

Mallinger, A., \& DeWyze, J. (1992). Too perfect: When being in control gets out of control. New York, NY: Faucet Columbine.

Millsted, R., \& Frith, H. (2003). Being large-breasted: Women negotiating embodiment. Women's Studies International Forum, 26, 455-465. http://dx.doi. org/10.1016/j.wsif.2003.08.003

Pisacane, A., \& Continisio, P. (2004). Breastfeeding and perceived changes in the appearance of the breasts: A retrospective study. Act Pædiatrica, 93, 1346-1348. http://dx.doi.org/10.1111/j.1651-2227.2004.tb02935.x
Raposio, E., Belgrano, V., Santi, P., \& Chiorri, C. (2016). Which is the ideal breast size? Some social clues for plastic surgeons. Annals of Plastic Surgery, 76, 340-345. http://dx.doi.org/10.1097/SAP.000000000000471

Rubin, L. R., \& Steinberg, J. (2011). Self-objectification and pregnancy: Are body functionality dimensions protective? Sex Roles, 65, 606-618. http://dx.doi.org/ 10.1007/s11199-011-9955-y

Sherry, S. B., Vriend, J. L., Hewitt, P. L., Sherry, D. L., Filet, G. L., \& Wardrop, A. A. (2009). Perfectionism dimensions, appearance schemes, and body image disturbance in community members and university students. Body Image, 6 , 83-89. http://dx.doi.org/10.1016/j.bodyim.2008.12.002

Skouteris, H., Carr, R., Wertheim, E. H., Paxton, S. J., \& Buncombe, D. (2005). A prospective study of factors that lead to body dissatisfaction during pregnancy. Body Image, 2, 347-361. http://dx.doi.org/10.1016/j.bodyim.2005.09.002

Swami, V., Cavelti, S., Taylor, D., \& Tovée, M. J. (2015). The Breast Size Rating Scale: Development and psychometric evaluation. Body Image, 14, 29-38. http://dx. doi.org/10.1016/j.bodyim.2015.02.004

Swami, V., \& Furnham, A. (2018). Breast size dissatisfaction, but not body dissatisfaction, is associated with breast self-examination frequency and breast change behaviours in British women. Body Image, 24, 76-81. http://dx. doi.org/10.1016/j.bodyim.2017.12.004

Swami, V., \& Mammadova, A. (2012). Associations between consideration of cosmetic surgery, perfectionism dimensions, appearance schemes, relationship satisfaction, excessive reassurance-seeking, and love styles. Individual Differences Research, 10, 81-94.

Swami, V., \& Tovée, M. J. (2013). Men's oppressive beliefs predict their breast size preferences in women. Archives of Sexual Behavior, 42, 1199-1207. http://dx. doi.org/10.1007/s10508-013-0081-5

Talmon, A., \& Ginzburg, K. (2018). "Who does this body belong to?” The development and psychometric evaluation of the body experience during Pregnancy Scale. Body Image, 26, 19-28. http://dx.doi.org/10.1016/j.bodyim. 2018.05.002

408
409
410
411
412
413
414
415
416
417
418
419
420
421
422
423
424
425

Please cite this article in press as: Lombards, C., et al. Motherhood status moderates the relationship between perfectionistic selfpresentation and breast size dissatisfaction. Body Image (2019), https://doi.org/10.1016/j.bodyim.2019.05.005 